\title{
Adrenal Cortical Carcinoma pT1 TNM Finding v8
}

National Cancer Institute

\section{Source}

National Cancer Institute. Adrenal Cortical Carcinoma pT1 TNM Finding v8. NCI

Thesaurus. Code C141090.

Tumor measuring $5 \mathrm{~cm}$ or less in greatest dimension, with no extra-adrenal invasion.

(from AJCC 8th Ed.) 